\title{
Constructing Professional Identity: Investigating Stress Factors and Resilience Experienced by EFL Novice Teachers
}

\author{
Krismalita Sekar Diasti \\ krismalita.sekar@gmail.com \\ Sanata Dharma University
}

\begin{abstract}
Several studies show that EFL novice teachers often feel stress as they encounter shock from the rapid shift of a student to a teacher. Stress experienced by EFL novice teachers occurs because of internal or external factors. Stress which cannot be regulated will result in teacher burnout that can lead them to leave the profession. This qualitative study intended to investigate EFL novice teachers' stress factors and coping strategies which influence their professional identity construction. The data was obtained by conducting an in-depth interview with three EFL novice teachers. The findings showed that EFL novice teachers experienced stress because of three factors, namely, personal, interpersonal, and organization factors. Despite feeling stress, EFL novice teachers demonstrated their abilities to cope with the circumstances. The participants elaborated how they cope with the situations as well as how stress factors influenced their identity as teachers. This study provides some suggestions for future researchers and EFL novice teachers.
\end{abstract}

Keywords: Teacher Identity, Teacher Professional Identity, Teacher Resilient, Teacher Stress

Received date: 11 Juni 2020

Article Info

Revised date: 2 Januari $2021 \quad$ Accepted date: 19 Januari 2021

\section{INTRODUCTION}

Teaching is one of the challenging vocations as teachers have always to be ready for the abrupt hindrance in the teaching and learning activities. Teachers bring their own beliefs and assumptions when they confront challenges in the classroom. Essentially, teacher identity is how a teacher defines who he/she is and embraces their characteristics which make them divergent from others as quoted from Berger and Le Van (2018) that "identity is strongly tied to the concept of self" (p. 2). Therefore, teacher identity is influenced by many aspects such as family background, school culture or experience.

Personal identity is closely related to professional identity although the difference between both of them remains unclear (Kuswandono, 2013), entirely because scholars define them differently. Novice teachers seem to experience the disconnection between their personal and professional identity. It happens as they encounter shifting from student teachers into real teachers. Moreover, novice teachers are in the process of cultivating their professional identity. As stated by Beauchamp and Thomas (2009) "novice teachers need to shape their new professional identity while at the same time enabling their personal identity to persist" (p. 49). Teachers encounter challenges in navigating themselves in the journey of constructing their professional identity. The challenges cause tension, stress, or burnout. Novice teachers tend to leave the job early since they could not alter challenging situation into positive experience (Meijer, de Graaf, \& Meirink, 2011). One of the coping strategies that teacher can implement is being resilient. Understanding resilience is pivotal to rebound from the difficult situation.

Resilience can be defined as the ability to recover from challenging circumstances. Day (2018) mentions that resilience is tied with the capacity to "bounce back from the trauma of adverse physical and psychologically threatening experiences, actions or events" (p. 67). Resilience is needed to prevent teachers from stress, tension, or burnout. In the teaching and learning process, teachers encounter incidents in the classroom whether positive or negative. Sometimes, a certain incident could imprint and become a bad memory for the teachers. Resilience is needed to help teachers reconcile with their past experiences. Indeed, teaching is considered as an emotional work in which teachers build a relationship with the students. The relationship has to be genuine in order to promote a successful teaching and learning process. The involvement of interplay relationship between teacher and students 
evoke both positive and negative emotion. Day (2018) emphasizes that teachers engage "in the activity as emotional labor" (p. 66). Emotional labor means that teachers manage their emotions to make it unnoticed by the students. Teachers' negative emotions can influence students in the learning process. Therefore, teachers have to leave their problems behind before coming to the classroom. As a result, they could teach enthusiastically and promote a supportive environment for students to learn. In other words, teachers manage their negative emotion and transform it into positive atmosphere.

This current study focuses on teachers' perceived stress factors. Stress in this particular research is defined as any condition which arouses negative emotions. Teachers experience stress in a condition where they feel fury, tense, anxious, frustrated or depressed (Kyriacou, 2001). Stress occurs because of many factors. Previous studies classified the causes of teachers stress. The major sources are students' misbehavior, deficient communication with colleagues or parents, time pressure, poor working condition, dissatisfaction of their salary, and a big number of students (Clipa \& Boghean, 2015).

One of the most obvious stress factors experienced by teachers is a heavy workload (Clipa \& Boghean, 2015). Teaching is considered as a demanding vocation since teachers will engage in completing abundant responsibilities. Despite teaching, teachers have to develop lesson plan, correct students' assignment, and report students' score. Teachers often bring their responsibilities home to finish it on time. Besides completing administrative tasks, teachers have to fulfill the demands of government, parents, and students. In the educational context of Indonesia, where the curriculum changes overtime, teachers have to be always ready for the demands requested by the government. Currently, the schools implement a curriculum which focuses on student-centered learning. Teachers are not the main source of knowledge but they are the facilitators (Harden \& Crosby, 2000). As facilitators, teachers are required to be flexible especially in this twenty-first century where we are surrounded by sophisticated technology. Teachers have to provide the students with any kinds of learning media and encouraging environment. The learning process is focused on outcome-based learning where the students can contribute to the development of a country in the future. "Schools are challenged to develop skill-sets in their students which focus on lifelong learning and employability" (Benede, 2015). Therefore, the teaching process is not only transferring knowledge but also cultivating students' soft skills. Teachers also get demand from parents. Parents always want their children to excel in the classroom. They care more about their children's academic achievement. Teachers might be asked by parents about their children's progress or performance (Rizqi, 2017). Sometimes it can be the complaints from parents towards the teachers. It can be imagined that being a teacher drains both physical and mental energy (Rizqi, 2017).

In the EFL context, teachers might feel stress since they have inadequate language competence (Mousavi, 2007). It is assumed that EFL teachers are proficient in English. Unlike native English teachers, EFL teachers might encounter several language issue difficulties, such as fluency, pronunciation, or grammar. Mousavi (2007) discovers another stressor for EFL teachers which is lack of confidence. Teachers are frequently considered as role model or perfect example for the students. As a result, teachers have to prepare themselves before teaching. However, EFL novice teachers often encounter unpredictable situations in the classroom which might lower their self-confidence (Mousavi, 2007).

Due to the demanding situations and EFL shortcomings aforementioned, stress is a condition that cannot be avoided by teachers. The most important things to be noted are that how teachers cope with stress and find an effective strategy to overcome it. Stress has a relation with coping strategies or resilience. As elaborated by Masten, Best, and Garmezy (1990) resilience is a form of successful adaptation despite challenging or threatening circumstances. In brief, resilience is pivotal for teachers, particularly novice teachers, to help them cope with the situation and being robust in the journey of professional identity construction.

Previous studies have explored teachers stress and resilience. Many cases show that novice teachers tend to resign within 5 years of teaching experience (Wal, Oolbekkink-Marchand, \& Schaap, 2019). The primary reason underlying it is that they are not ready to encounter challenges in the classroom. Teachers have learned theories or methods of teaching. However, they are lack to bridge the theories and practice (East, 2014). Teachers also have had the opportunity to do teaching practicum. Yet, the real teaching happens when they become real teachers.

Rizqi (2017) mentions that major factor of Indonesia teachers' stress is the changeable curriculum. Indeed, Indonesia curriculum changes overtime. Stress experienced by teachers in a long 
condition will cause teachers burnout (Sovitriana, Santosa, \& Hendrayani, 2019). Sovitriana, et al. (2019) conducted a research on Junior High school teachers in Indonesia. The results of the study present that having heavy workload, fulfilling demands, and dealing with students cause stress which leads into burnout if teachers are not able to cope with imbalance situation (Sovitriana et al., 2019). Environment can also contribute to the stress factor. For instance inadequate teaching resources, facilities or government support. Those factors happen in rural areas of Indonesia (Nurwidodo, Husamah, Rahardjanto, Mas'odi, \& Mufrihah, 2017; Lomi \& Mbato, 2020; Florida \& Mbato, 2020). Study conducted by Nurwidodo, et al. (2017) reveals that teachers in rural area are resilience to cope with insufficient situation. The salary of private school teachers in rural area is often postponed since the students prefer to pay the school tuition at the end of the semester (Lomi \& Mbato, 2020). Despite challenges and tough situation which can evoke stress, teachers are still willing to teach as they believe their contribution will help their students achieve a better future. However, none of the studies above has delved more profoundly in the scope of EFL novice teachers. This study was conducted to add valuable contribution to the previous literature. The research questions were formulated as follows: (1) What are the sources of stress faced by EFL novice teachers during their professional identity construction? (2) How do stress factors affect their professional identity construction?

\section{LITERATURE}

\section{Teacher Professional Identity}

Identity has a tight-knit relationship with self-concept. Teacher identity is interpreted as a description on how teachers define who they are along with the beliefs or values that they hold. Identity is a fluid aspect which can be affected by several factors. Beijaard, Meijer, and Verloop (2004) emphasize that professional identity is "an ongoing process of integration of the personal and professional sides of becoming and being a teacher" (p. 113). Beliefs which teachers hold lead them to choose teaching method or technique in which they believe the certain method will help their students achieve their goals.

Professional identity is multidimensional aspect. There are various components that influence it, namely, motivation, self-efficacy, sense of responsibility, commitment to teaching, and perception of expertise (Berger \& Van, 2017, p. 164). Motivation highlights the reasons why a person decides to be a teacher. Motivation comes from internal and external factors. Internal motivation of teachers involves teachers' passion in teaching and willingness to help the students. Teachers who are driven by internal motivation perceive teaching as an inner calling. External motivation is an encouragement from other people or seeing pervious teacher as a role model (Berger \& Van, 2017). Self-efficacy is teacher belief on their ability in carrying teaching task and administrative work (Berger \& Van, 2017). Besides teaching in the classroom, teachers have to fullfil several demands given to them, namely, "fullfiling student motivation, student achievement, relationships with students and teaching quality" (Lauermann \& Karabenick, 2013, p. 17). Teachers will encounter different challenges and difficulties in teaching process. However, teachers must have commitment to teaching. Commitment to teaching can be defined as to what extent teachers feel connected with their profession (Lamote \& Engles, 2010, p. 7). Perception of expertise is defined as evaluating selves (Berger \& Van, 2017). Reflective practice is integrated in teaching in order to support teachers' self-evaluation. By doing so, teachers could gauge their teaching performance as well as find out the solution towards a particular problem.

\section{Resilience}

Teachers face circumstances which drain their physical and emotion. They react differently towards the circumstances. Being adaptable means teachers are resilient. Day (2018) define resilience as the ability to rebound. Every teacher is capable to endure the tough situation and they are brave to embrace every hindrance that they experienced.

Resilience links to individual ability to regulate their emotion (Rizqi, 2017). Someone is resilient if he is surrounded by stressful circumstance in which they do not have control over it (Rizqi, 2017). Teachers need to be resilient as Nurwidodo, et al. (2017) affirm that "the ability to survive in difficult conditions is a remarkable thing" (p. 49).

\section{Teacher Stress}

Stress is a condition where a person feels pressure. A particular circumstance could provoke stress which result in negative emotion, namely, anger, anxiety, tension, frustration or depression 
(Kyriacou, 2001). Teacher stress occurs due to several factors. Clipa and Boghean (2015) classify two factors of teacher stress, namely, environmental and individual factors. Environmental factors occur due to stimuli around teachers. Environmental factors encompass poor working condition, inadequate teaching resources, and lack of government support (Clipa \& Boghean, 2015). Individual factors are factors come within teachers which include teachers' beliefs and abilities to maintain relationship as well as assigned task (Clipa \& Boghean, 2015).

Aside from environmental and individual factors, students contribute to the cause of teacher stress, namely, students' misbehavior, a big number of students in a classroom, or unmotivated students (Clipa \& Boghean, 2015). The primary cause of Indonesia teacher stress is the changeable curriculum (Rizqi, 2017). The changeable curriculum demands teachers to adjust their teaching activities. This factor can contribute to teacher stress factor as "there is an imbalance between demands from environment and available resources of an invidual" (Sovitriana et al., 2019, p. 27). In brief, there are three major factors of teacher stress, namely, personal, interpersonal, and organization factors (Prilleltensky, Nerr, \& Bessell, 2016). Personal factors include teacher self-efficacy and ability (Prilleltensky et al., 2016). Interpersonal factors encompass teachers' relation with supervisor, students, parents, and colleagues (Prilleltensky et al., 2016). Organization factors involve school culture, management of the school, and government regulation (Prilleltensky et al., 2016). Negative emotions experienced by teachers should be managed properly. Stress which cannot be managed will cause burnout and lead into leaving the vocation.

\section{METHOD}

This study intended to examine teacher stress factors, teacher resilience, and how stress factors influence their professional identity. This study employed qualitative method research with an in-depth interview for the data collection. The participants for this research were three EFL novice teachers from different private schools in Jakarta, Indonesia. The participants were chosen by using purposive sampling. They were contacted by the researcher via Whatsapp application to participate in this study. Those novice teachers consisted of two senior high school teachers and one primary school teacher. The participants have been teaching for 1-2 years. The researcher employed an in-depth interview for gathering the data by inquiring the participants to reflect on their teaching experience and share their critical incidents. To protect participants' confidentiality, pseudonyms were given. The researcher conducted an online interview through WhatsApp application since the participants' locations were difficult to be reached by the researcher. Each interview session was recorded and transcribed by the researcher. After obtaining the data, the researcher tried to find themes and highlight the underlying information based on the data. The researcher classified the data on novice teachers' stress factors, coping strategies as well as identity construction. The emerged categories were elaborated narratively in the following subchapter.

\section{FINDINGS AND DISCUSSION}

The following discussion intends to answer the research questions, namely: (1) what are the sources of stress faced by EFL novice teachers during their professional identity construction? (2) how do stress factors affect their professional identity construction? Based on the data collection, there were three major findings drawn in this study: (1) EFL novice teachers encountered stress due to personal, interpersonal, and organizational factors (2) EFL novice teachers are able to bounce back from difficult situations by demonstrating different coping strategies (3) stress experienced by EFL novice teachers support their professional identity construction, particularly in cultivating their teaching skills. An indepth explanation is elaborated as follows.

\section{Stress Factors of EFL novice teachers}

\section{Personal Factor}

According to Prilleltensky, et al. (2016), there are three major factors of teacher stress, namely, personal, interpersonal, and organization factors. The findings present that novice teachers experienced stress because of those three factors. The participants have different opinions about their stress factors. Table 1 presents stress factors experienced by EFL novice teachers. 
Table 1: Novice EFL teachers' critical incidents

\begin{tabular}{lll}
\hline Question & Alesia & Gita \\
\hline What makes you feel stressful? & The moment that makes me & The students are more proficient than me. It \\
& feel stressed is when several & is a pressure for me since I cannot exceed \\
& students do not want to listen & them. No matter how hard I try, they are still \\
to me. & better than me \\
\hline
\end{tabular}

Novice teachers tend to prepare themselves before teaching in the classroom and come to the class with their expectations. However, after coming to the class, and problems arise their confidence will be affected. The ambiance of the class is completely different from their expectations. Based on the findings, students' poor behavior contributes to the stress factor of EFL novice teachers. This particular issue is corresponding with Clipa and Boghean (2015). They discover that students' poor attitudes in the classroom often made teachers stress. Another similar finding uncovered by Prilleltensky, et al. (2016) that novice teachers are often stressed due to student discipline. Novice teachers have inadequate teaching experience. As a result, they encounter difficulty in classroom management. Classroom management and student discipline are two main reasons for novice teachers to leave the profession early (Prilleltensky et al., 2016). Teacher higher education programs should give more opportunities for pre-service teachers to develop teaching skills through teaching practice. Critique is addressed to teacher higher education programs as they provide minimum teaching practice to pre-service teachers. As a result, novice teachers fail to bridge theories and practice (Jones \& Ryan, 2014; Kuswandono, 2014; Nguyen, 2017). Pre-service teachers have to be provided with abundant teaching experience to enhance their teaching skills. Providing pre-service teachers with teaching practice is pivotal as they can learn from their experience.

Teachers' low self-efficacy can influence novice teachers in performing a particular task. Teacher efficacy is defined as a teacher's ability to manage and perform a specific action in order to accomplish teaching tasks (Tschannen-Moran, Hoy, \& Hoy, 1998). The participants of this study teach in accordance with their expertise yet one of the participants feels lacking of her proficiency. Novice teachers often perceive that they have inadequate language proficiency and teaching skills (Lomi \& Mbato, 2020). The main reason is the language barrier. Novice teachers often feel stressed out since they have to teach English subject through English. Hence, novice teachers should have a desire to learn and enrich themselves as teaching is a part of lifelong learning.

Interpersonal Factor

Prilleltensky, et al. (2016) argues that novice teachers might encounter challenges in dealing with students' behavior as well as having relationship with colleagues and parents. These interpersonal factors contribute to perceived stress for EFL novice teachers. Based on the Table 2, EFL novice teacher encounters obstacle to build relationship with another teacher.

Table 2: Novice EFL teachers' critical incidents

\begin{tabular}{ll}
\hline Question & Sinta \\
\hline What makes you feel stressful? & $\begin{array}{l}\text { Some teachers who always talk behind me because I always complain about } \\
\text { the school system. I have ever argue with one of the senior teachers because } \\
\text { she would like to manipulate the students' scores }\end{array}$ \\
\hline
\end{tabular}

The participant has to tackle a negative relation with colleagues. Novice teachers encounter difficulties in maintaining a relationship with colleagues. They often have different views and perspectives from senior or experienced teachers due to the divergent experience and educational background. Sinta, who is an idealist teacher, believes that what she learned in college should be implemented when she teaches in the classroom. From the statements, it can be concluded that novice teacher has a different perspective from an experienced teacher. Moreover, novice teachers might feel pressured due to the relation with experienced teachers. This finding is corresponding with Lomi and Mbato (2020) who reveal that a novice teacher has a negative relationship with her colleagues in which she was debated as she got more classes than the other senior teachers. A negative relation with colleagues will obstruct novice teachers' growth. Senior or experienced teachers ought to provide guidance for novice teachers since they cannot solve classroom problems by themselves. 
Constructing Professional Identity: Investigating Stress Factors and Resilience Experienced by EFL

Novice Teachers (Krismalita Sekar Diasti)

\section{Organization Factor}

School culture and management contribute to teachers' stress factors. Besides, additional work becomes one of teacher stress factors. Teachers who are given a bunch of administrative work will not focus on their students since they tend to prioritize the accomplishment of administrative work. Table 3 shows that EFL novice teachers have to complete several administrative work which might become additional burden for them.

Table 3: Novice EFL teachers' critical incidents

\begin{tabular}{ll}
\hline Question & Sinta \\
\hline What makes you feel stressful? & The school culture in my workplace. The principal always gives direction \\
& $\begin{array}{l}\text { in sudden. Sometimes, I get shock and feel overwhelmed. Sudden } \\
\text { administrative work adds another burden for me. }\end{array}$ \\
\hline
\end{tabular}

The previous statements show that administrative work can incriminate novice teachers. The finding of this study is supported by Berger and Van (2018) who emphasize that completing administrative work can be stressful which leads to teacher burnout. By the same token, Lomi and Mbato (2020) state that focusing only on administrative work can hider teachers in advancing their teaching skills. Teacher profession is a demanding work since teachers are not only teaching but also completing administrative document. Indeed, administrative work impedes teachers to concentrate more on their students. Moreover, sudden administrative work grants burden to novice teachers.

\section{EFL Novice Teachers Resilience}

Teacher resilience is teacher's ability to cope with arduous circumstances. Teachers should be able to endure the troublesome circumstances and willing to embrace every hindrance that they experienced. Teachers should be able to reconcile with their past experiences. Based on the findings, EFL novice teachers have diverse strategies to cope with their stress. In Table 4, EFL novice teachers elaborate their coping strategies to tackle the challenging situations.

Table 4: Novice EFL teachers' coping strategies

\begin{tabular}{llll}
\hline Question & Sinta & Alesia & Gita \\
\hline How do you deal with & I tell my difficulties to my I just need private time & When I have many \\
adversity in your working & friends. They always give and to keep a distance from & problems, I just \\
circumstances? & advice to me, but to be honest, I the problems. & allocate my time to \\
& just want to quit from this job. & do a reflection. \\
\hline
\end{tabular}

Based on the findings, it can be concluded that colleagues' support bring positive impact on EFL novice teachers. External support, specifically from colleagues, family, supervisors, is priceless for novice teachers (Sovitriana et al., 2019). Sovitriana, et al. (2019) discovered that social support given to novice teachers can be in the form of willingness to listen to them, advice, or suggestion. Social support can reduce novice teachers' stress level as they will feel being loved and appreciated (Sovitriana et al., 2019). Another coping strategy is doing reflection. Indeed, reflective practice helps teachers to be aware of surroundings (Kuswandono, 2014). Novice teachers are provided with space to pause and think about their situation. Reflection helps teachers to find solutions towards their problems as well. By doing reflection teachers could look back in order to look forward or anticipate what might happen in the future.

Further, the findings reveal that one of the participants plan to quit from the job due to her inability to cope and recover from the pain or difficulties.Teachers who are not able to reach the level of reconciliation would leave the vocation early. This case becomes the concern of many parties. Previous researchers reveal that novice teachers tend to leave the job within five years (Wal et al., 2019). Therefore, teacher higher education programs have to equip pre-service teachers with teaching skills that make them survive in teaching vocation (Jones \& Ryan, 2014). Novice teachers will encounter problems that are stressing and challenging. When beginning teachers could not endure the situation then they prefer to leave the profession (Nuwridodo et al., 2017). Novice teachers have to regulate and maintain their emotions when they face stressing and uncontrollable situations. They should be mindful that being vulnerable is acceptable. Being aware of their vulnerability lead novice teachers to reconcile with their past. 


\section{EFL Novice Teachers Professional Identity Construction}

\section{EFL Novice Teachers Motivation}

Teachers will always face problems and challenges in the classroom. By developing professional identity, teachers will be wiser to solve every problem (Day, 2018). Professional identity is a multidimensional aspect. There are various components that influence it, such as motivation, selfefficacy, sense of responsibility, commitment to teaching, and perception of expertise (Berger \& Van, 2017, p. 165). When the participants were asked about their motivation to be a teacher, they expressed different reasons which could be seen in Table 5 .

Table 5: Novice EFL teachers' motivation

\begin{tabular}{lll}
\hline Question & Alesia & Gita \\
\hline What are the underlying & I want to be a teacher & Being a teacher is not my passion. My motherforced me \\
reasons make you since I was inspired by & to be a teacher. She told me that if I studied in English \\
become a teacher? & my mother. & graduation program, I would get a job easily. After I \\
& & well-known schools in Jakarta. During less two-year \\
& teaching, my motivation changed. I enjoyed having a \\
& relationship with students and I had found love in \\
& teaching. \\
\hline
\end{tabular}

Motivation holds a paramount role that drives people to do something. Teacher motivation boosts them to act towards the accomplishment of the teaching task. According to Richardson and Watt (2018), teacher motivation plays an important part in shaping their professional identity. The participants of this study are driven by internal and external motivation. Teacher internal motivation comes from within them. It is stated by Alesia that she was inspired by her mother. This finding is supported by Upa and Mbato (2020) who state that family and previous experience can inspire someone to choose teacher as his career. Gita mentions that her motivation to become a teacher is because she finds confront in having relations with her students. Although she felt forced in the beginning she found genuine love in her relationship with the students. Indeed, teachers can befriend with the students. Teachers' close relationship with the students can influence their motivation in teaching (Tehseen \& Hadi, 2015). They discover that teachers who have high motivation will perform well which results in good quality of education for students. Teachers who have motivation and positive emotions in teaching promote the enhancement of students' achievement.

EFL Novice Teachers 'Assumption of their Professional Identity

In the journey of developing teacher professional identity, novice teachers encounter challenges and problems which can discourage them. Table 6 shows that the participants are resilient as they are able to cope with the inconvenient situation.

Table 6: Novice EFL teachers' identity

\begin{tabular}{|c|c|c|c|}
\hline Question & Sinta & Alesia & Gita \\
\hline $\begin{array}{l}\text { How do define } \\
\text { a good or an } \\
\text { ideal teacher? }\end{array}$ & $\begin{array}{l}\text { In my opinion, an ideal } \\
\text { teacher is someone who } \\
\text { understands the material and } \\
\text { gives an explanation to the } \\
\text { students clearly. Moreover, } \\
\text { she can befriend with the } \\
\text { students. }\end{array}$ & $\begin{array}{l}\text { For me, a good } \\
\text { teacher is someone } \\
\text { who is able to } \\
\text { understand students } \\
\text { feelings r and } \\
\text { characteristics. I } \\
\text { always try to do that } \\
\text { by having a genuine } \\
\text { relationship with } \\
\text { them. }\end{array}$ & $\begin{array}{l}\text { Good teachers are those who are } \\
\text { willing to help students in achieving } \\
\text { a brighter future. They must be } \\
\text { sincere in doing that. I always try to } \\
\text { be a sincere teacher who always } \\
\text { guides every student. Nowadays, } \\
\text { many teachers are losing their } \\
\text { identity. They care more on high } \\
\text { salary than students' achievement. }\end{array}$ \\
\hline $\begin{array}{l}\text { Do you think } \\
\text { that as a } \\
\text { teacher you } \\
\text { are now better } \\
\text { than before? }\end{array}$ & $\begin{array}{l}\text { I cannot say that I am a good } \\
\text { teacher. I feel like there is no } \\
\text { change within me since the } \\
\text { first day I taught here. I have } \\
\text { not known every student's } \\
\text { characteristics well. }\end{array}$ & $\begin{array}{l}\text { I think I am a better } \\
\text { teacher now, } \\
\text { particularly in my } \\
\text { teaching skills. }\end{array}$ & $\begin{array}{l}\text { Sure, we learn from experience and } \\
\text { I feel like I am much better than } \\
\text { before. I learned from my students } \\
\text { as well. They taught me how to be a } \\
\text { good teacher and I always try to } \\
\text { improve myself. }\end{array}$ \\
\hline
\end{tabular}


Facing hard circumstances makes them vulnerable. Yet, the participants are willing to embrace their weaknesses since they believe their work can contribute to students' future. When they were asked about a good teacher, they gave similar opinions. Most of the participants emphasize that having a good relationship with the students help them to become a good teacher. It is in line with what Palmer (2003) states that relationship with the students is more pivotal than the teaching method used in the class. Teachers have to build an authentic relationship with the students first before coming into the teaching and learning process. A comfortable atmosphere created by teachers provides the students with an enjoyable learning process. Moreover, novice teachers shared their teaching performance and abilities. They had different opinion related to their teaching performance and abilities.

Based on the findings, the majority of EFL novice teachers perceive that they develop themselves, particularly in teaching skills. Professional identity is a dynamic process. Consequently, teachers will always construct and reconstruct their identities. Novice teachers are expected to have a desire to grow and enrich themselves in order to fulfill the demands given to them. In the progress of developing their professional identity, novice teachers have to be able to cope with the circumstances. One of the coping strategies is by doing reflection. Reflection is believed as a powerful tool in assisting teachers' professional growth (Jones \& Ryan, 2014; Lubis, 2017; Rozimela \& Tiarina, 2018). By doing reflection, teachers are aware of their strengths and weaknesses. Novice teachers have to always evaluate every teaching performance in order to be aware of their progress as well as limitation. Moreover, novice teachers can improve themselves by looking at their past experiences dealing with troublesome circumstances.

\section{CONCLUSION AND RECOMMENDATION}

\section{Conclusion}

Based on the findings, the researcher concluded that the stress factors of EFL novice teachers were because of personal, interpersonal, and organizational factors. Personal factors occurred since EFL novice teachers were not able to manage the classroom since they had insufficient teaching experiences. As a result, students tended to demonstrate a poor attitude in the classroom. Moreover, EFL novice teachers had a low self-efficacy. EFL novice teachers encountered shifting from being a student to a teacher. Therefore, they felt shocked as they should be able to master the material as well as know the teaching method. Interpersonal factor involved the difficulty in having and maintaining a relationship with senior or experienced teachers. Organization factors included the management of the school or school culture. Additional administrative work could contribute to EFL novice teachers' stress factors and hinder them to explore innovative teaching methods as well as develop themselves. Despite the challenges that they encountered, EFL novice teachers were resilient as they could cope with the situation and remain in the profession. The participants believed that their work would contribute to students' better future. For future researchers, it will be worthwhile to undertake a study in a similar area on the correlation between teachers' stress factors and resilience. For EFL novice teachers, it is pivotal to regulate negative emotions and transform painful experience into a positive experience.

\section{Recommendation}

Nonetheless, this study has several drawbacks. First, this study was conducted involving small participants. Therefore, the results of this present study could not be generalized. Future researchers who are captivated to investigate similar scope have to involve bigger participants. Second, this research merely focuses on teachers' stress factors and coping strategies. The correlation between teachers' stress level, resilience, and job satisfaction is worth to be explored. Regarding the issue discussed in this study, it is essential for teacher education institutions to prepare and construct pre-service teachers' professional identity which would assist the face hardships in the teaching vocation. Further, pre-service teachers have to be aware of the fact that teaching is interlinked with vulnerability and resilience. Preservice teachers will always encounter interferences in their daily teaching basis. Therefore, it is notable for higher teacher education to emphasize the prominence of becoming a reflective practitioner. By engaging in reflective practice, pre-service teachers will evaluate their teaching performance and find coping strategies to tackle adversity that occurred in teaching vacation. 


\section{REFERENCES}

Beauchamp, C. \& Thomas, L. (2009). Understanding teacher identity: An overview of issues in the litterature and implications for teacher education. Cambridge Journal of Education, 39(2), 175189.

Beijaard, D., Meijer, P. C., \& Verloop, N. (2004). Reconsiding research on teachers' professional identity. Teaching and Teacher Education, 20, 107-128.

Benede, L. (2015). Teachers' critical reflective practice in the context of twenty-first century learning. Open Review of Educational Research, 2(1), 42-54.

Berger, J. \& Van, K. L. (2018). Teacher professional identity as multidimensional: Mapping its components and examining their associations with general pedagogical beliefs. Educational Studies, 45(2), 163-181.

Clipa, O. \& Boghean, A. (2015). Stress factors and solutions for the phenomenon of burnout of preschool teachers. Social and Behavioral Sciences, 180, 907-915.

Day, C. (2018). Research on teacher identity (Schutz, P. A., Hong, J., \& Francis, D. C. Eds). New York: Springer.

East, M. (2014). Mediating peagogical innovation via reflective practice: A comparison of pre-service and in-service reachers' experiences. Reflective Practice, 15(5), 686-699.

Florida, N. A. \& Mbato, C. L. (2020). Novice versus experienced teachers: How they transform their vulnerability into professional identity in an Indonesian junior high school. Journal of Educational Research and Evaluation, 4(1), 8-16.

Harden, R. M. \& Crosby, J. (2000). The good teacher is more than a lecturer - the twelve roles of the teacher. Medical Teacher, 22(4), 334-347.

Jones, M. \& Ryan, J. (2014). Learning in the practicum: Engaging pre-service teachers in reflective practice in the online space. Asia-Pasific Journal of Teacher Education, 42(2), 132-146.

Kuswandono, P. (2013). The journey of becoming a teacher: Indonesian pre-service teachers reflecting on their professional learning. Unpublished thesis. Melbourne: Monash University.

Kyriacou, C. (2001). Teacher stress: Directions for future research. Educational Review, 53(1), 27-35.

Lamote, C. \& Engels, N. (2010). The development of student teachers' professional identity. European Journal of Teacher Education, 33(1), 3-18.

Lauermann, F. \& Karabenick, S. A. (2013). The mearning and measure of teachers' sense of responsibility for educational outcomes. Teaching and Teacher Education, 30(1), 13-26.

Lomi, A. N. K. \& Mbato, C. L. (2020). Struggles and strategies in constructing professional identity: The first-year teaching experiences of Indonesian EFL novice teachers. Journal of English Education and Teaching, 4(1), 1-19.

Lubis, A. H. (2017). Teaching reflection: A voice from Indonesian EFL teachers. International Journal of English Language Teaching and Linguistics, 2(1), 29-39.

Nguyen, C. D. (2017). Connections between learning and teaching: EFL teachers' refletive practice. Pedagogies: An International Journal, 12(3), 237-255.

Nurwidodo, Husamah, Rahardjanto, A., Mas'odi, Mufrihah, A. (2017). Teacher resilience in remote islands area: A case study in small Pagerungan island Sumenep regency, Indonesia. Journal of Education and Learning, 11(1), 47-56.

Mal, M . V. D, Oolbekkink-Marchand, H. W., Schaap, H., \& Meijer, P. C. (2019). Impact of early career teachers' professional identity tensions. Teaching and Teacher Education, 80, 59-70. 
Constructing Professional Identity: Investigating Stress Factors and Resilience Experienced by EFL

Novice Teachers (Krismalita Sekar Diasti)

Masten, A. S., Hubbard, J. J., Gest, S. D., Tellegen, A., Garmezy, N., \& Ramirez, M. (1999). Competence in the context of adversity: Pathways to resilience and maladaption from childhood to late adolescence. Development and Psychopathology, 11, 143-169.

Meijer, P., De Graaf, G., \& Meirink, J. (2011). Key experiencs in student teachers' development. Teachers and Teaching, 17(1), 115-129.

Mousavi, E. S. (2007). Exploring teacher stress in non-native and native teachers of EFL. English Language Teacher Education and Development, 10, 33-41.

Palmer, P. J. (2003). The courage to teach. New Jersey: John Wiley \& Sons.

Prilleltensky, I., Neff, M., \& Bessell, A. (2016). Teacher stress: What it is, why it's important, how it can be alleviated. Theory Into Practice, 55(2), 104-111.

Richardson, P. W. \& Watt, H. M. (2018). Teacher professional identity and career motivation: A lifespan perspective. In Research on teacher identity (pp. 37-48). Springer, Cham.

Rizqi, M. A. (2017). Stress and resilience among EFL teachers: An interview study of an Indonesian junior high school teacher. TEFLIN Journal, 28(1), 22-37.

Rozimela, Y. \& Tiarina, Y. (2018). The impact of reflective practice on EFL prospective teachers' teaching skill improvement. The Journal of Language Teaching and Learning, 1, 18-38.

Sovitriana, R., Santoso, A. D., \& Hendrayani, F. (2019). Teacher burnout and self esteem in Tangerang's Junior High School teachers. International Review of Management and Marketing, 9(2), 26-30.

Tehseen, S. \& Hadi, N. U. (2015). Factors influencing teachers' performance and retention. Mediterranean Journal of Social Sciences, 6(1), 233-244.

Upa, Y. \& Mbato, C. L. (2020). English teacher identity construction: Indonesian teachers' motivation and strategies in teaching English for special needs students. Professional Journal of English Education, 3(2), 311-321. 